\title{
HOMOTRANSFOBIA: UM HORROR QUE NÃO CHOCA A SOCIEDADE BRASILEIRA
}

\author{
Márcio José Testolin ${ }^{1}$ \\ Margarete Fagundes Nunes ${ }^{2}$ \\ Gustavo Roese Sanfelice ${ }^{3}$
}

Resumo: Este artigo tem como objetivo estes exemplos de horrores trágicos discutir, sob a perspectiva da diversidade contra as pessoas LGBT+. Discutimos a e dos direitos humanos, a desvalorização da vida humana pela sustentação da homotransfobia na sociedade brasileira. Trata-se de um estudo bibliográfico que tem como base a discussão do conceito de horror trágico aplicado à reflexão dos direitos humanos. A experiência do horror trágico, que poderia chocar os indivíduos e os grupos e lhes estimular possíveis rupturas com seus códigos morais, quando vivenciada e associada à população $\mathrm{LGBT}+$, não é capaz de romper com a tradição homotransfóbica. Utilizamos como dados secundários o construção da subjetividade masculina através de um processo heteronormativo, assim como, o atual cenário brasileiro, onde movimentos políticos, religiosos e conservadores atuam em defesa da manutenção deste contexto homotransfóbico para tentarmos compreender esta indiferença da sociedade para com as necessidades da população LGBT+.

Palavras-chave: Diversidade Sexual. Gênero. Homotransfobia. Sexualidade. Direitos humanos. relatório elaborado pelo Grupo Gay da Bahia (2018) e, principalmente, o caso de assassinato da travesti Dandara, sendo

Abstract: This article aims to discuss, under the diversity and human rights

\footnotetext{
1 Mestrando em Diversidade Cultural e Inclusão Social, graduado em Educação Física Licenciatura pela Universidade Feevale, RS. Atuou como bolsista de iniciação científica vinculado ao grupo de pesquisa Corpo, Movimento e Saúde desde maio de 2015.

${ }^{2}$ Doutora em Antropologia Social pela Universidade Federal de Santa Catarina (2009). É do corpo docente permanente do Programa em Diversidade Cultural e Inclusão Social e do Mestrado profissional em Indústria Criativa, ambos da Universidade Feevale/RS. Integra os Grupos de Pesquisa: Metropolização e Desenvolvimento Regional e Ambiente e Sociedade.

${ }^{3}$ Possui graduação em Educação Física Licenciatura Plena pela Universidade Federal de Santa Maria (2001); mestrado em Ciência do Movimento Humano pela Universidade Federal de Santa Maria (2002) e doutorado em Ciências da Comunicação/Universidade do Vale do Rio dos Sinos/UNISINOS (2007) . Atualmente é professor Titular da Universidade Feevale.
} 
perspective, the depreciation on human life by sustaining homo/transphobia in Brazilian society. This is a bibliographical study based on discussion of the tragic horror concept applied to the reflection on human rights. The experience of tragic horror, that could shock the individuals and groups and stimulate them possible ruptures with their moral codes, when experienced and associated to LGBT+ population, it is not capable of disruption with homo/transphobic tradition. We utilized as secondary data the report elaborated by the Gay Group of Bahia (2018) and, mainly, the case of the murder of the transvestite Dandara, these being examples of tragic horrors against LGBT+ people. We discuss the construction of male subjectivity through a heteronormative process, as well as, the current Brazilian scenario, where political, religious and conservative movements act in defense of the maintenance of the homo/transphobic context to try to comprehend this society's indifference to the needs of the LGBT+ population.

Keywords: Gender. Homo/transphobia. Human rights. Sexuality. Sexual Diversity.

\section{Introdução}

Este artigo tem como principal objetivo discutir, sob a perspectiva da diversidade e dos direitos humanos, a desvalorização da vida humana pela manutenção/sustentação

da homotransfobia na sociedade brasileira. Partimos do raciocínio de Débora Diniz (2001), a qual recupera o conceito de "horror trágico" da filosofia grega clássica, para aplicá-lo no contexto das sociedades contemporâneas e discute, em especial, a capacidade deste em chocar as pessoas e lhes estimular possíveis mudanças e rupturas com suas tradições, práticas culturais e códigos morais de sua sociedade. Nos filiamos a essa concepção para situarmos que, em alguns casos, o horror trágico pode estabelecer conflitos, mas não necessariamente provocar mudanças e rupturas estruturais. Em seguida, tentamos compreender porque tratandose da homotransfobia, o horror trágico não consegue ter força suficiente para causar tais mudanças e rupturas. Para isto, utilizamos a sociedade brasileira como exemplo, discutindo dados do relatório elaborado pelo Grupo Gay da Bahia (2018) e, principalmente, o caso de assassinato da travesti Dandara, 
ocorrido no dia 15 de fevereiro de 2017 , que teve repercussão nacional devido à crueldade demonstrada no crime, o qual consideramos um horror trágico capaz de chocar qualquer sociedade que valorize os direitos humanos.

\section{A banalização da homofobia e do horror trágico}

No Brasil contemporâneo, assistimos a uma escalada da violência e à banalização daquilo que supostamente poderia provocar ojeriza e aversão no que se refere aos crimes cometidos contra as populações LGBT+ (lésbicas, gays, bissexuais, transexuais entre outras possibilidades de identidades de gênero e/ou sexualidade). Concomitante a alguns avanços pontuais conquistados por essas populações nas últimas décadas, especialmente após a redemocratização do país, no final dos anos 1980, passa a ocorrer uma reação conservadora a essas parcas conquistas relacionadas ao campo dos direitos civis e políticos e aos direitos econômicos e sociais (união estável, reconhecimento da conjugalidade para efeito de direitos sociais como herança, planos de saúde etc.) e culturais (direito à expressão da sua orientação sexual). Muitas das reivindicações ocorridas nos contextos locais e nacionais estão articuladas com uma política internacional de Direitos Humanos, que ganha espaço na sociedade brasileira na década de 1990 .

Especialmente nos anos 2000, acentuam-se movimentos organizados em defesa de códigos morais tradicionais, que vão desde a defesa da conceituação clássica de família, designada como composta tão somente por um homem e uma mulher e a prole que dessa relação resultar, até a retomada de alguns debates teóricos já superados como a ligação da homossexualidade a patologias e, portanto, passíveis de tratamento e cura, seja esta cura propiciada pelo campo da medicina ou por conversão religiosa (NATIVIDADE \& OLIVEIRA, 2009).

A disputa presidencial no Brasil, em 2018, colocou no segundo turno das eleições candidatos em polos antagônicos, um representando setores mais conservadores que mobiliza comunidades morais (SEGATO, 2006) “defensoras da família tradicional e dos bons costumes", outro que aglutina forças mais progressistas e sensíveis a discursos ligados a uma cosmopolítica global (LINS RIBEIRO, 2009) como a dos direitos humanos. A adesão de 
grande parte da população à candidatura presidenciável de um político que já se afirmou publicamente como homofóbico, declarando em entrevista para a grande mídia: "sou homofóbico, sim, com muito orgulho!", abre espaço para um certo "pacto pretensamente coletivo" legitimador de concepções e práticas discriminatórias, vexatórias e agressivas contra a população LGBT+.

Em primeiro lugar, queremos ressaltar que, conforme indica Velho (2003), os indivíduos de comportamentos desviantes, no caso desta discussão, em específico as pessoas $\mathrm{LGBT}+$, foram vistos, historicamente, sob uma perspectiva patológica, comumente classificados como anormais, ou insanos. Portanto, para algumas comunidades morais, a heterossexualidade corresponde a uma verdade absoluta, que se fundamenta em discursividades acerca da normalidade, tradição e costumes (SEGATO, 2006).

Diniz (2001) utiliza a obra de ficção Possessing the secret of joy de Alice Walker de 1992, a qual narra a fictícia história de Tashi, uma mulher Olinka, vivendo nos Estados Unidos, cuja a mãe não lhe submeteu ao procedimento tradicional de toda mulher Olinka, a mutilação genital. Devido a isto, Tashi não se sentia uma verdadeira Olinka, uma vez que, ao contrário das demais mulheres de seu grupo étnicoracial, não passou pelo rito tradicional considerado uma verdade absoluta para aquela sociedade. $\mathrm{O}$ motivo para que sua mãe não lhe submetesse ao tradicional ritual fora a morte da irmã, Dura, por conta deste procedimento de mutilação genital. Em meio a diversos dilemas morais, o sentimento de Tashi era que só se tornaria uma verdadeira Olinka após submeter-se à tradição. Porém, quando isto enfim ocorre, devido ao choque durante a mutilação (não apenas no aspecto físico, mas sobretudo psicológico), Tashi, perturbada, também foi capaz de romper com a tradição Olinka e a colocá-la em risco, assassinando Madre Lissa (a responsável por realizar o rito tradicional) considerada a grande mãe de toda a raça e detentora de quase todas as memórias mais importantes que constituem a história Olinka, haja vista que não utilizam a escrita para registros de sua história.

Portanto, na discussão proposta por Diniz (2001), pode se perceber dois principais pontos de rupturas com as tradições. O primeiro é o da mãe de Tashi, ao sofrer com a perda de sua filha, 
Dura. E o segundo, o da própria Tashi, envolvida em um dilema moral que a deixou vulnerável psicologicamente. Ambos motivados pelo que a autora considera claramente como horror trágico. Sua argumentação é de que fatos horríveis, capazes de chocar, impactam as pessoas e as possibilitam romper com verdades até então absolutas em suas tradições:

Por um lado, a história de Tashi mostra como o horror trágico é a condição irrevogável para a mudança das crenças com status de verdade, ou seja, a experiência do horror trágico é o único meio reservado aos personagens moralizados para que experimentem o princípio do acaso e habilitem-se a modificar suas certezas (DINIZ, 2001: 21).

Podemos destacar algumas importantes rupturas históricas que tiveram como principal motivação o horror trágico. Ainda que toda e qualquer mudança neste nível se dê com o tempo e através de muitas disputas e tensões, é possível dizer que, no âmbito internacional, ou no que Cardoso de Oliveira (2000) situa como macroesfera, temos a Declaração Universal dos
Direitos Humanos, assim como, no âmbito nacional, cuja o mesmo autor classifica como meso-esfera, temos a Lei Maria da Penha, ambos exemplos de conquistas que tiveram como principal motivador, o referido horror trágico.

Observando o primeiro exemplo, a Declaração Universal dos Direitos Humanos ocorre após a Segunda Guerra Mundial, a qual causou horrores trágicos dos mais diversos, como torturas, genocídios, entre outros. Ainda que, como indica Lins Ribeiro (2009), seja questionável a pretensão de universalidade dos direitos humanos, pode se considerar que este foi o maior avanço na prevenção e redução de abusos e crimes contra a vida humana, principalmente aqueles cometidos por agentes e agências sociais poderosos/as e violentos/as.

No caso da Lei Maria da Penha, a mesma surge por decorrência da sociedade brasileira apresentar-se violenta, cruel e criminosa contra as mulheres, muitas das quais são vítimas de violência no próprio ambiente doméstico e familiar (Decreto-Lei $\mathrm{n}^{\circ}$ 
11.340, de 7 de agosto de 2006) ${ }^{4}$. Na imensa maioria dos casos, a impunidade aos agressores prevalecia. Somente após uma série de denúncias e notificações internacionais, sobretudo em relação ao horror trágico da história de uma das vítimas em particular, Maria da Penha, que o legislativo aprovou uma lei específica para violência doméstica e familiar contra a mulher (SANTOS, 2010).

Certos grupos conseguem, através de suas lutas e reinvindicações, discutir suas pautas e até mesmo conquistar implementações de leis e/ou políticas públicas, amplas ou específicas, mais eficientes na redução da violência. Contudo, cabe questionar, por que se tratando de homotransfobia, as discussões propostas pela população LGBT+, como as possibilidades de investimento em uma educação para o respeito e a equidade de gênero $e$ diversidade sexual, assim como legislações e políticas públicas a fim de reduzir a violência contra este grupo ainda não culminaram na presença dos temas na educação básica e nem em medidas legais e ações significativas

\footnotetext{
${ }^{4}$ A Lei no 11.340, de 7 de agosto de 2006 ou, Lei Maria da Penha, criou mecanismos para coibir a violência doméstica e familiar
}

contra homotransfobia ou medidas similares?

\section{A experiência e a perpetuação do horror trágico}

De acordo com relatório elaborado pelo Grupo Gay da Bahia (2018), a violência por homotransfobia, ou, pelo menos suas notificações, têm aumentado a cada ano. Os casos de mortes de pessoas LGBT+ são registrados pelo grupo há 38 anos. Através destes dados, é possível observar um aumento alarmante das notificações durante este período. Em 2007, foram registradas 142 mortes motivadas por homotransfobia. Apenas 10 anos mais tarde, em 2017, foi contabilizado o maior índice destes 38 anos de relatórios, atingindo 445 mortes. Destas, 387 foram assassinatos e 58 suicídios. Portanto, percebe-se que há um ódio marcado pelo desprezo às identidades de gênero e/ou sexualidade não hegemônicas enraizado na tradição desta sociedade heteronormativa e expressado inclusive através de violência direta e indireta,

contra a mulher (Decreto-Lei ${ }^{\circ} 11.340$, de 7 de agosto de 2006). 
tanto em aspectos físicos quanto psicológicos.

Cabe ressaltar que o relatório é subnotificado, pois não há banco de dados oficial, uma vez que homotransfobia ou homofobia não são tipificadas como crimes específicos no Brasil. Portanto, lembramos que este relatório expõe apenas parte da realidade violenta contra a população $\mathrm{LGBT}+$, sendo provável que os casos reais ultrapassem significativamente estes registrados. Também não há como comprovar se a violência aumentou, de fato, ou se passou a haver mais possibilidade de reconhecimento de alguns crimes como sendo movidos por discriminação de orientação sexual, alterando, assim, as notificações.

Crimes como estes que são cometidos pelo simples motivo de aversão e intolerância às identidades de gênero e/ou sexualidade de pessoas LGBT+ não podem ser compreendidos fora de um contexto específico da sociedade em que ocorrem porque também são produzidos por ele (MASIERO, 2013). Segundo argumenta Woodward (2013), as identidades dos sujeitos são construídas, tanto simbólica quanto socialmente e não existem de modo independente, pois são relativas, dependem da diferença em relação as outras para existirem. De acordo com a autora, as diferenças são marcadas simbolicamente e, cabe ressaltar, possuem vínculo com as condições sociais e materiais. Em determinados contextos, algumas diferenças são atribuídas de maior importância que outras, sendo assim, capazes de marcarem certos grupos e/ou sujeitos como inimigos ou tabus. Nestes casos, as marcações simbólicas atuam no sentido de definir quais destes grupos e/ou sujeitos devem ser incluídos ou excluídos e, consequentemente, desprivilegiados de condições sociais e materiais, a incluir aqui a dignidade humana.

Tal processo se dá de acordo com os discursos legitimados por cada sociedade que, conforme Foucault (2007), é capaz de produzir e sustentar suas verdades, através de múltiplas práticas discursivas que legitimam e exercem um poder regulatório sobre seus membros. Neste sentido, o autor indica que é através das relações de poder que se dão em cada contexto que as sociedades acolhem determinados discursos e os elegem como suas verdades, legitimando assim suas consequências. No caso das questões de 
gênero e sexualidade, nossa sociedade tem como discurso tradicional, verdadeiro e absoluto, um entendimento heteronormativo, onde se supõe que todas as pessoas do sexo feminino devem se tornar mulheres quanto a identidade de gênero e sentirem atração sexual por homens e vice-versa (SEFFNER, 2014). Em meio a este contexto tão bem definido e estruturado, as pessoas desviantes destas normas, seja por serem seu oposto ou por estarem em suas fronteiras, são atribuídas de um status monstruoso, pois desestabilizam a ordem social e provocam situações dignas de pânico moral (MISKOLCI, 2007; LOURO, 2013).

A construção da subjetividade masculina como violenta e homofóbica ocorre através de processos discursivos, sociais e sempre relacionais. Boris, et al (2012), ao discutirem tal processo, consideram que há um abismo forjado nas relações entre o que é feminino e masculino, tendo o homem, ao longo da construção de sua masculinidade, o “dever" de comprovar que não é uma mulher, não é um bebê e, muito menos, um homossexual, pois tais condições o colocariam num papel de mulher, considerado inferior. Portanto, não diferente de outras mais antigas, as sociedades contemporâneas também possuem seus ritos de construção da subjetividade masculina que induzem os homens a comportamentos machistas, violentos e homofóbicos a fim de, através da imposição de sua virilidade, sustentarem os privilégios sociais e a posição superior de poder na relação hierárquica com as demais identidades de gênero e de sexualidade.

Esta tradição, ao mesmo tempo em que pode ser enfraquecida por uma crise de identidade contemporânea, por ela, também é reforçada. Em especial porque, nos últimos anos, têm surgido movimentos feministas e de minorias de gênero e sexualidade que provocam questionamentos quanto a legitimidade desta heteronormatividade e lutam por conquistas sociais, de direitos e igualdade, o que por sua vez, desestabiliza a estrutura heteronormativa e colabora para busca de uma sociedade menos machista. Porém, provoca receio ou medo de perdas de privilégios simbólicos e sociais nos grupos mais conservadores (BORIS, et al 2012).

Estes processos possuem tamanha força que, como indica Goffman (1988), os indivíduos que, de alguma forma, não correspondem às normas sociais estabelecidas como 
ideais, ainda que em determinados momentos possam pensar em defender esta diferença, vista externamente como "defeito", tendem a se sentirem indignos e inferiorizados, pois são padrões naturalizados com tamanha força que despertam nos sujeitos o desejo de estarem de acordo com as normas que são quase inquestionáveis para não passarem por tanto sofrimento. Portanto, ainda que as sociedades não tenham firmados os seus valores e suas regras em documentos ou qualquer outro lugar, projetam considerações e atribuem valores hierárquicos aos indivíduos nas mais diversas situações do quotidiano. Os indivíduos desviantes destas normas são banidos de determinados ambientes sociais e instituições, pois seus comportamentos ou suas identidades não atendem as exigências para aceitação. Desta forma, tendem a sofrer com um processo de "correção dos seus defeitos" ou se manterem rejeitados e segregados destes ambientes. Isto ocorre, sobretudo quando o "defeito" é visível, pois estes sujeitos estigmatizados sofrem uma humilhação especial por demonstrarem abertamente seus "problemas" e suas

\footnotetext{
${ }^{5}$ Mais sobre o crime e a condenação dos acusados na reportagem do G1. https://g1.globo.com/ce/ceara/noticia/cinco-
}

situações "vergonhosas" (GOFFMAN, 1988).

Muitas dentre as 445 mortes de LGBT+ podem confirmar este estigma e esta rejeição aos desviantes da norma. Contudo, escolhemos um caso que teve repercussão nacional por seus requintes de crueldade, o da travesti Dandara, de 42 anos de idade, pois o consideramos um horror trágico que, assim como tantos outros crimes, já deveria ter sido suficiente para chocar a sociedade e causar uma ruptura com tais padrões preconceituosos. O crime ocorrido em $15 / 02 / 2017$, foi gravado e divulgado nas redes sociais por um dos acusados. O vídeo mostra um grupo de 8 homens que torturam com tapas, chutes, pedradas, pauladas e verbalmente humilham a vítima completamente indefesa. Também gravam a execução final, com tiros de revólver e se desfazem do corpo $(\mathrm{G} 1,2018)^{5}$.

Mesmo diante de muitos horrores trágicos como o exemplo de Dandara, a sociedade brasileira não demonstra capacidade de se chocar, de experimentar o acaso, como sugere Diniz (2001), e romper com sua tradicional

dos-acusados-pela-morte-da-travestidandara-sao-condenados.ghtml 
discriminação e intolerância com as diversidades de gênero e de sexualidade. $\mathrm{O}$ atual contexto que se seguiu após os dados deste relatório, indica o sucesso e o respaldo de algumas comunidades morais (SEGATO, 2006) às ações de grupos conservadores sendo empreendidas nos poderes legislativo e executivo e, também, nas redes sociais e nas ruas.

Podemos destacar o sucesso destes grupos conservadores nas discussões sobre a inclusão ou exclusão do termo gênero nos Planos Nacional, Estaduais e Municipais de educação, assim como, também ocorreu sobre a Base Nacional Comum Curricular (BNCC), conforme vimos anteriormente quando citamos o projeto Escola sem homofobia. Estes grupos obtiveram sucesso no seu objetivo de estimular uma pressão política contra a presença dos conteúdos de gênero nos Planos Educacionais, na BNCC e na prática das salas de aula. Tais movimentos que ocorreram em diversos contextos também surtiram efeito nas comunidades, causando, como consequência, uma pressão dos/as responsáveis de alunos/as sobre as escolas, intimidando assim professores/as que pretendessem discutir as temáticas gênero e sexualidade em suas aulas (REIS \& EGGERT, 2017).

Além destas questões supracitadas, também podemos considerar um retrocesso no que diz respeito à luta por uma sociedade mais equânime, os fatos ocorridos em relação ao museu Queer, em 2017, em Porto Alegre/RS. A exposição promovida pelo Santander Cultural, denominada "Queermuseu cartografias da diferença na arte da brasileira", tinha como mote a diversidade sexual. Diversas manifestações de intolerância e censura ocorreram nas redes sociais e em locais públicos, protagonizadas por grupos religiosos e pelo MBL - Movimento Brasil Livre, o que culminou no fechamento da exposição em Porto Alegre e sua rejeição em diversas outras cidades.

Ainda que a Constituição Federal do Brasil (1988) tenha como seus princípios fundamentais a dignidade da pessoa humana, a construção de uma sociedade livre, justa e solidária, assim como, a promoção do bem de todos/as, sem discriminações de qualquer tipo, gênero, sexualidade, raça/etnia, nacionalidade, religiosidade ou outras sejam quais forem e uma 
educação básica que, segundo a mesma, eduque para a cidadania e para promoção humanística, o que podemos perceber na prática, é uma reação conservadora, contrária a estes princípios constitucionais e da Declaração Universal dos Direitos Humanos, cuja o Brasil é signatário.

As opiniões conservadoras manifestadas nas redes sociais e nos protestos contra os conteúdos de gênero na educação, ou a favor da censura ao museu Queer, quando aliadas ao autoritarismo de políticos que utilizam de seus cargos para propor, defender e aprovar legislações que sustentem os privilégios de seus grupos, têm como efeito a tentativa de impor a toda a sociedade seus pensamentos, suas considerações do correto, do verdadeiro, do santo, do admirável, sobretudo, do permitido. Com isto, o que explanamos aqui, é a percepção de que movimentos de grupos conservadores extremistas se articulam com políticos atuantes, especialmente com cargos legislativos, a fim de utilizar a força do Estado em prol de seus interesses, para imposição e hegemonia de suas crenças e valores próprios, o que vem colaborando para sustentação deste contexto criminoso de

\section{homotransfobia (NATIVIDADE \&} OLIVEIRA, 2009).

Parte destes posicionamentos são consequências das ações de algumas religiões, principalmente evangélicas, que convocam seus fiéis a se posicionarem politicamente, pressionando membros do legislativo para que reprovem projetos de leis que contribuiriam de alguma forma para conquistas e avanços de direitos da população LGBT+ (NATIVIDADE, 2013). Enquanto isso, além da não inclusão dos conteúdos de gênero na BNCC, também ocorreu, em 2014, o arquivamento da PLC 122/2006, cuja proposta era criminalizar a homofobia. Líderes de grupos religiosos argumentaram que o projeto poderia colocar em risco a liberdade de expressão de crença e religião, uma vez que muitas delas são contrárias à homossexualidade. Houve protestos e pressões políticas, impedindo a tramitação do projeto apelidado pelos religiosos de "lei da mordaça" (BOMFIM, 2011).

O que se constata é uma reação aos movimentos que buscam dar visibilidade à livre orientação sexual. Ao invés da exposição, propõe-se o silenciamento e a repressão, tanto das 
homoafetividades, homo e transsexualidades quanto da construção identitária fora do padrão estabelecido, o heterossexual. Algumas iniciativas de discussão acerca dos conteúdos de gênero e de orientação sexual no âmbito da escola básica foram amplamente questionadas por alguns setores mais conservadores, que viram nessas iniciativas uma ameaça à preservação da "família tradicional". Em 2011, o projeto Escola sem homofobia, proposto pelo Ministério da Educação, que visava fornecer subsídios aos professores e professoras para trabalhar a diversidade sexual no âmbito escolar, sofreu inúmeras críticas, o que fez o governo, na época, recuar e optar pela não execução do projeto. Ainda assim, o projeto recebeu a alcunha de kit gay e, desde então, passou a ocupar espaço, sobretudo, nas redes sociais, por meio de ideias da suposta existência de uma "ideologia de gênero" ou "doutrinação de gênero" nas escolas, onde professores/as estimulariam crianças e adolescentes ao desenvolvimento de práticas homossexuais, "desvirtuandoos/as" do caminho do bem e dos bons costumes (REIS \& EGGERT, 2017). No pleito eleitoral de 2018, estas fake news espalharam-se numa dimensão sem precedentes, fragilizando, ainda mais, o difícil espaço de discussão destas temáticas no âmbito escolar e na sociedade em geral.

Esta onda de reação do conservadorismo também pode ser um sinal de que os avanços e conquistas das minorias de gênero e sexualidade foram significativos a ponto de desestabilizar os grupos privilegiados historicamente. Afinal, tais ações de repressão ocorrem porque indicam um medo ou receio dos grupos religiosos e conservadores em geral, os quais não querem, em hipótese alguma, correrem o risco de terem os seus discursos ameaçados e enfraquecidos de poder, pois consequentemente isso acarretaria na perda da legitimidade de seus valores morais, de suas normativas sociais e até mesmo da configuração de sua principal instituição, a família matrimonial, como a única verdadeira (MELLO, 2006).

Contudo, ainda que tenham ocorrido tais avanços em relação às diversidades, eles são contestáveis, uma vez que podem ser considerados avanços superficiais. Cabe aqui refletirmos sobre a crítica proposta por Sodré (2006) ao pensamento ocidental moderno e aos avanços ocorridos através de políticas multiculturalistas que, para o autor, 
insistem em discutir a diferença sob a perspectiva de uma concepção abstrata que permite apenas uma compreensão superficial, de modo somente intelectualista, cujo os objetivos se resumem a obter uma tolerância, ou intenções voltadas ao mercado e à economia, "sem chegar ao núcleo do problema, que é a verdadeira compreensão (aproximação e aceitação) do diferente concreto.” (SODRÉ, 2006: $7)$.

\section{Considerações Finais}

Cabe refletir que a existência de diversas comunidades morais, com seus valores particulares, costumes e práticas culturais, nos permite pensar a possibilidade de haver distintas interpretações e sensibilizações do horror trágico, de acordo com as particularidades de uma ou outra destas comunidades morais. Isto, talvez colabore para uma compreensão desta incapacidade do referido horror trágico (a homotransfobia) em chocar parte da sociedade brasileira, uma vez que muitas das comunidades morais que a compõem podem ter naturalizado diferentes valorações que não lhes possibilitam a sensibilidade e a indignação com este tipo de violência. Contudo, toda e qualquer comunidade moral está sujeita aos efeitos da pulsão ética que permite aos seus indivíduos abordar criticamente suas leis e seus códigos morais, contestando e considerando-os inadequados, o que pode promover um distanciamento do seu leito cultural e a transformação dos costumes destas comunidades morais que fazem parte. Portanto, ainda que os indivíduos estejam sujeitos às valorações e aos códigos morais de suas comunidades, isto não ocorre de modo inescapável (SEGATO, 2006).

Somos plenamente humanos porque a mesma cultura que nos implanta os chips de valores morais e as práticas semiautomáticas a nos habilitar como membros de uma comunidade moral e "naturais" de uma sociedade juridicamente constituída, também nos equipa com as ferramentas que permitem detectar refletidamente esses mesmos chips e desativá-los (SEGATO, 2006: 222).

Por fim, não queremos aqui defender especificamente a criminalização da homofobia ou 
homotransfobia, o qual consideramos que seria o termo mais adequado. Mas provocarmos a reflexão e o questionamento já propostos no início deste texto sobre a incapacidade e/ou desinteresse de nossa sociedade em se chocar com os horrores trágicos cometidos contra população LGBT+e, a partir disto experimentar romper com suas tradições para buscar tentativas de reduzir a violência por homotransfobia e, principalmente, instituir medidas que visem a promoção da equidade de direitos e dignidade, independente de gênero e/ou orientação sexual.

Esta reflexão torna-se necessária, uma vez que, em grande parte dos casos de homo, bi ou transexualidade, as famílias e a sociedade isolam, esquecem e destituem de dignidade estas pessoas diferentes. Portanto, antes mesmo de uma morte real, já são deixados para morrer (FERRARI \& SEFFNER, 2009).

Diante dos avanços de uma ideologia conservadora na sociedade brasileira contemporânea, por meio da organização política de alguns grupos capazes não somente de desagregar e/ou desconstituir alguns avanços importantes dos direitos sociais dessas populações, mas de ameaçar a integridade física destes sujeitos, haja vista a persistência de crimes cometidos contra estas populações, cabe ao movimento LGBT+ e seus aliados a composição de estratégias de resistências e enfrentamento, que articulem as dimensões de uma micro, meso e de uma macroética

(CARDOSO

DE

OLIVEIRA, 2000).

\section{Referências Bibliográficas}

Bomfim, Silvano Andrade do (2011), "Homossexualidade, Direito e Religião: da pena de morte à união estável. A criminalização da homofobia e seus reflexos na liberdade religiosa", Revista Brasileira de Direito Constitucional, 18(1), 71-103.

Boris, Georges Daniel Janja Bloc et al (2012), "Os rituais da construção da subjetividade masculina”, O público e o privado, 19, 17-32.

Brasil. Constituição (1988), “Constituição da República Federativa do Brasil”. Brasília, DF: Senado Federal. Centro Gráfico. 292 p. 
Cardoso de Oliveira, Roberto. O

Trabalho do Antropólogo. Brasília:

Paralelo 15; São Paulo: Unesp, 2000.

Decreto-Lei $\mathrm{n}^{\circ}$ 11.340, de 7 de agosto de 2006. Diário Ofical da União de 8.8.2006. Brasilia.

Diniz, Debora (2001), “Antropologia e os limites dos direitos humanos: o dilema moral de Tashi, in Regina Reis Novaes; Roberto Kant de Lima, (Org), Antropologia e direitos humanos. Niterói: EdUFF,17-28.

Ferrari, Anderson; Seffner, Fernando (2009), ““A morte e a morte”... dos homossexuais", Revista Gênero, 10(1) 191-217.

Foucault, Michel (2007), Microfísica do poder. 24. ed. Rio de Janeiro, RJ: Graal. G1 (2018), "Cinco dos acusados pela morte da travesti Dandara são condenados". Página consultada a 15.06.2018, em https://g1.globo.com/ce/ceara/noticia/ci nco-dos-acusados-pela-morte-datravesti-dandara-sao-condenados.ghtml.

Goffman, Erving (1988), Estigma: notas sobre a manipulação da identidade deteriorada. 4. ed. Rio de Janeiro, RJ: Guanabara Koogan.

Grupo Gay da Bahia (2018), "Pessoas LGBT mortas no Brasil: Relatório de 2017”. Salvador, Bahia. Consultado a 23.07.2018, em https://homofobiamata.files.wordpress.c om/2017/12/relatorio-2081.pdf.

Lins Ribeiro, Gustavo (2009), "Diversidade cultural enquanto discurso global” Avá, Posadas, 15, 9-39.

Louro, Guacira Lopes (2013), Um corpo estranho: ensaios sobre sexualidade e teoria queer. 2 ed. Belo Horizonte, MG: Autêntica.

Masiero, Clara Moura (2013), "Homofobia: história e crítica de um preconceito" Emblemas, 10(2), 125-146.

Mello, Luiz (2006), "Familismo (anti) homossexual e regulação da cidadania no Brasil”, Estudos feministas, 14(2), 497-508.

Miskolci, Richard (2007), "Pânicos morais e controle social", Cadernos pagu, 28, 101-128. 


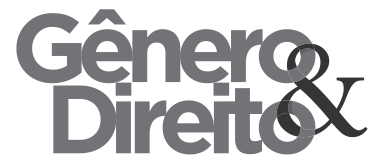

Periódico do Núcleo de Estudos e Pesquisas sobre Gênero e Direito

Centro de Ciências Jurídicas - Universidade Federal da Paraíba

V. 8 - $\mathrm{N}^{\circ} 01$ - Ano 2019

ISSN | 2179-7137 | http://periodicos.ufpb.br/ojs2/index.php/ged/index
Natividade, Marcelo Tavares (2013),

"Homofobia religiosa e direitos LGBT:

Notas de pesquisa" Latitude 7(1), 33-51.

Natividade, Marcelo Tavares; Oliveira, Leandro de (2009), “Sexualidades ameaçadoras: religião e homofobia (s) em discursos evangélicos conservadores", Sexualidad, Salud y Sociedad-Revista Latinoamericana, 2, 121-161.

Reis, Toni; Eggert, Edla (2017), "Ideologia de gênero: uma falácia construída sobre os planos de educação brasileiros", Educação \& Sociedade, 38(138) 9-26.

Santos, Cecília MacDowell (2010), "Da delegacia da mulher à Lei Maria da Penha: absorção/tradução de demandas feministas pelo Estado", Revista crítica de ciências sociais, 89, 153-170.

Seffner, Fernando (2014), "Sexualidade: isso é mesmo matéria escolar?", Teoria e Prática da Educação, 17(2) 67-81.

Segato, Rita Laura (2006), "Antropologia e direitos humanos: alteridade e ética no movimento de expansão

dos 16 universais", Mana, 12(1), 207-236.

Sodré, Muniz (2006), "Diversidade e diferença”, Revista Científica de Información y Comunicación, 3(1), 515.

Velho, Gilberto (2003), Desvio e divergência: uma crítica da patologia social. 8ed. Rio de Janeiro. Zahar.

Woodward, Kathryn (2013), Identidade e diferença: uma introdução teórica e conceitual, in Tomaz Tadeu da Silva (Org.), Identidade e diferença: a perspectiva dos estudos culturais. 14. ed. Petrópolis, RJ: Vozes,.7-72 